\title{
Management and Control of Classroom for Effective Teaching-Learning Process in Tertiary Institutions: Policy Implications
}

\author{
Amos Oyetunde Alabi \\ Directorate of Educational Services, Bowen University \\ Iwo, Nigeria
}

Received: Oct. 9, 2019 Accepted: Nov. 21, $2019 \quad$ Published: November 21, 2019

doi:10.5296/jse.v9i4.15742ＵRL: https://doi.org/10.5296/jse.v9i4.15742

\begin{abstract}
The paper examines the importance of management and control of the classroom for effective teaching-learning process in tertiary institutions. Classroom or lecture room is one of the most important facilities in tertiary institutions being the pedagogical home of instruction. Lecture room may be physical as in the case of a four-wall room and it may be abstract as in the case of on-line teaching.

Classroom management and control are affected by psychosocial, physical and teaching methods. Each of those factors plays a very significant role in the management and control of class/lecture room for effective teaching-learning process. Each of them can make or mar the teaching-learning process depending on how the lecturer understands and handles them.

The paper, however, recommends some steps to be taken by lecturers to manage and control the classroom for effective teaching-learning process. Some of these are; the teacher being a model to the students should endeavour to know the students very well and by names, build good, cordial and lively relationship with the learners helps students to develop positive confidence in themselves, prepare well for the lectures, create conducive learning atmosphere in the lecture room and set some rules, among others.

The paper considers some policy implications of management and control of the classroom for effective teaching and learning processes on the proprietor, management, staff and students in a tertiary institution.
\end{abstract}

Keywords: classroom, classroom management, management, teaching environment, teaching and learning. 


\section{Introduction}

Management is an important aspect of human life. Every sphere of life or endeavour needs proper management. Individual lives equally need proper management. When there is no proper management there will be chaos and when there is chaos there will be no development, no progress, and hence no meaningful purpose to be achieved. Management, therefore, ensures proper coordination of an endeavour so that that endeavour fulfils its objectives or purpose of its existence. Control, on the other hand, has to do with exercising influence or authority over someone/thing or to suggest or dictate the behaviour of someone/thing.

Classroom management and control, therefore, refer to the process of creating favourable conditions to facilitate teaching-learning as well as regulating the social behaviours of the students. As the teacher properly coordinates all the resources available in facilitating instruction, he does it with a measure of authority as the instructor in the school.

Teaching-learning process perhaps is one of the major endeavours of educational institutions. The process if not well managed cannot fulfil the desired objectives but if properly managed will lead to the achievement of the purpose of the endeavour.

\section{The classroom and Its Importance}

The classroom is a kind of learning environment. The classroom which in this context is the traditional classroom is an institutional setting for teaching and learning. According to Amirul, Ahmad, Yahya, Abdullah, Noh, \& Adnan (2013), a learning environment refers to the space allocated for classrooms, science laboratories, open spaces or offices. The classroom is a four-walled room in an educational institution where students and teachers meet for academic activities. While the teacher teaches or imparts knowledge, the students learn. It can, therefore, be regarded as the workshop for both teachers and students.

Advance in technology has however moved teaching and learning process beyond the closure of a four-walled room to have online teaching and learning which allows students to learn at their own pace and yet meet up with the set educational objectives. The use of the traditional classroom cannot be underestimated. Even in the online system of learning, there is a learning model regarded as the flipped classroom. In the flipped classroom model, while the learning management system (LMS) which is usually a web-based platform gives the lecturers access to upload or post-lecture materials and course wares on the LMS, the students have the access to download the materials and attempt assignments outside the classroom setting. This encourages the students to develop a high sense of good orientation, autonomy, and behavioural engagement, problem-solving skills, independence, and personal student-generated examples. The flipped classroom moves lectures outside the classroom and moves homework and practice with concepts to the classroom via learning activities (Strayer, 2007; Enfield, 2013). Thus, even in the online learning system, there is still an adoption of the traditional classroom in the teaching and learning process.

The term classroom is more apt for primary and secondary institutions whereas, for tertiary institutions, lecture halls, seminar rooms, laboratories, workshops, tutorial classes/rooms are preferred. The management and control of the classroom, therefore, is the prerogative of the 


\section{Ml Macrothink}

teachers. This is more real in primary and secondary schools where a teacher and his pupils are assigned to a classroom for use all through a year. However, in a tertiary institution, it is not so.

The culture, in the tertiary institution, is the allocation of a classroom or lecture hall for a lecture at a specific time of the day such that there can be a group of students (lectures) using the space (lecture hall) for the number of lecture hours available in the day. With this arrangement, no group of students or lecturers can lay claim to any classroom and take full control of it as it is done in primary and secondary schools.

Nevertheless, at whatever level of education, what takes place in a classroom or lecture room is the process of teaching and learning.

\section{Dynamics affecting classroom management and control}

In identifying the factors affecting effective classroom management and control we adapted Gardiner (1989) model for studying educational environments in this study. The model identifies physical, psychosocial and IT (teaching) environments as the components that make up the education environment.

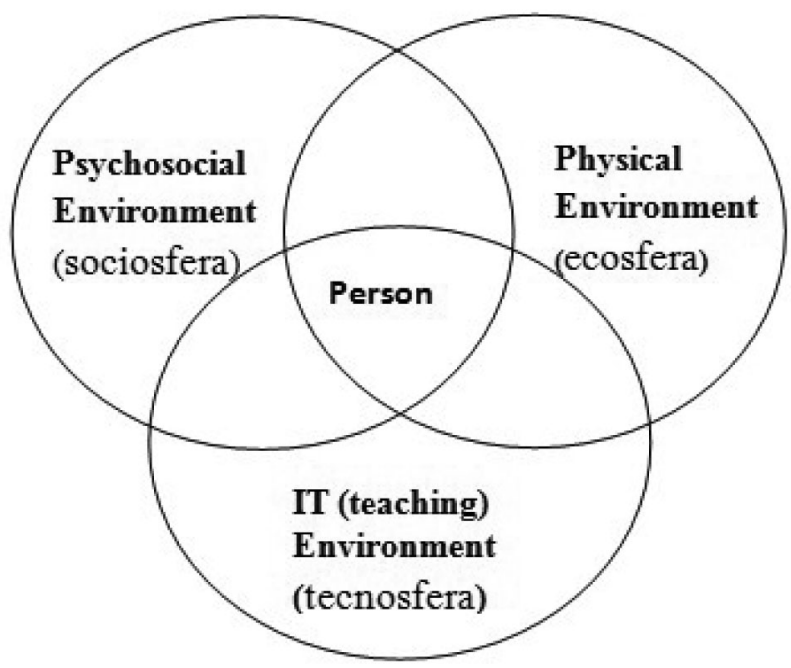

Figure 1. A conceptual model for studying educational environments Adapted from Gardiner (1989, p. 28)

The model shows three overlapping circles in which every one of them described as ecosfera, sociosfera and tecnosfera. Ecosfera is associated with the physical environment and the students around him. Sociosfera was associated with the outcome of individual interactions with others in their environment, while tecnosfera described as a man-made learning environment. This model proposes the joint consideration of physical and psychosocial factors in the environment while considering information about the specific educational context. Thus, in our study, we identified the factors affecting effective classroom 
management and control under the categories, physical environment, psychosocial and teaching method environment.

\section{The Physical environment}

The physical environment refers to the physical properties of the lecture room such as the walls, floor, ceiling, lighting, fans/air conditioners, interactive boards, chairs, and tables, etc. The physical environment factor involves ensuring the conduciveness of the teaching environment.

The physical environment has an impact on students' health, enjoyment, and learning. Also, there is a significant relationship between the physical aspects of the classroom environment with students' enjoyment and learning. Thus, the physical aspect of the classroom should be given attention to classroom management and control. (Ahmad \& Amirul, 2015)

This physical arrangement of the classroom is one of the things to ensure. According to Hannah (2013), the students should be arranged in groups to allow them to interact and stay focused at the same time for them, work with partners on specific assignments as well as class projects in cases where group discussions are necessary. The sitting arrangement should then be easily identifying disruptive students. Classroom sitting arrangements should encourage the active participation of students during lectures. Furthermore, Wannarka \& Ruhl (2008) in their study suggested that the nature of the academic task and the type of behaviour should dictate the sitting arrangement.

Another important issue in this category is ensuring a sizeable number of students in a class at a time. There could be cases of overcrowding in the class which could be a result of high enrolment of students and could lead to a shortage of the adequacy of instructional material. Marais (2016) in his study highlighted that an overcrowded class has a negative influence on managing classroom disciplines. It could be stressful as it could take time to get learners to settle down and handle misconduct among students. The effect in overcrowded class, students could become unmanageable. Students would not participate in learning activities due to a lack of motivation. A variety of teaching methods cannot be practiced in an overcrowded class and active participation or learner-centered activities are not achievable in an overcrowded class. Also, in an overcrowded environment, there tends to be an increase in temperature, which in turn could result in influencing social misbehaviours such as aggression. There could also be a case of physiological problems (respiratory diseases or other infectious illnesses) (Shah \& Inamullah, 2012; Opoku-Asare et.al. 2014).)

We also identified lighting of the classroom as an important factor in the physical environment category of factors that affects effective classroom management and control. (Samani \& Samani, 2012) in their study found that there is a significant relationship between lighting and students' performance. Also, (Gilavand, Gilavand \& Gilavand, 2016) in their research found out that lighting has a significant impact on learning and achievement. Insufficient illumination could make students sleepy and lose focus on their subject easily. Light control is also important to avoid discomfort. A well-designed and lightened environment makes people happy and energises and vice versa 


\section{$\Lambda$ Macrothink}

There should be a balance between natural light and artificial lighting. The best quality of light comes from the combination of daylight or natural light and artificial lighting for learning. Daylight can enhance colour and appearance of objects. However, it should be noted that for teaching to be effective teachers should be able to adjust lighting quickly to respond to changing educational needs. The need might be for group discussion, flipped classroom which requires brighter light than just presentation. (Erwine \& Heschong, 2002; Hui \& Cheng, 2008).

Lastly, under this category, we consider the need for instructional materials. These are items that are needed to impart information to students in the teaching-learning process. This includes videos, laboratory equipment, textbooks, newspaper, magazines, and picture albums. They could also be regarded as teaching aids.

The use of instructional materials encourages students' participation. They promote retention and arouse learners' interest and give them a better understanding of the concepts they are taught. (Effiong \& Igiri, 2015; Alabere, 2017) in their works identified that there is a significant influence of the use of instructional materials on the academic performance of students.

\section{Psychosocial Environment}

This category includes the teacher, students, and resource persons in interpersonal relationships and interaction in the classroom. It involves ensuring a friendly environment for the student. This involves the teachers setting necessary rules for the course/class, student-teacher relationship, communication, teachers' motivation. Anderson, Hamilton \& Hattie (2004) in their study highlighted that the social environment of the classroom impacts significantly on students' behaviour and academic performance.

Teachers should endeavour to create a good relationship with the students. According to (Marzano and Marzano, 2003) the teacher-student relationship is characterized by specific teacher behaviours which include exhibiting an appropriate level of dominance, exhibiting an appropriate level of cooperation and be aware of the high needs of students. They went further to also make some points which include, the teacher should talk informally with students before, during and after the class about their interest, encourage students to participate in discussions and interaction. In a situation where the teacher cannot provide an environment in which students actively participate, some students will be segregated, bored, or show misbehaviour which would affect the teaching-learning process. (Pane, 2010)

Also, they should make eye contact with students. During lectures, they should talk to students not to the screen, the book or the board. The more they make eye contact the closer relationship. They could use eye contact as a correction technique too. Eye contact helps teachers to establish goals and develop objectives for students. A good relationship between teacher and students is necessary for problem-solving. They should attribute the ownership of an idea to the student who initiated it; this would serve as an encouragement for them. (Marzano and Marzano, 2003; Barati, 2015; Khan, Mohammad, Shah \& Farid, 2016) 
Another important factor to note in this category is the use of class rules. According to (Marzano and Marzano, 2003) teachers must establish clear rules and procedures and provide consequences for students' behaviour. Clear and explicit rules for personal, respectful behaviour are important for students' participation in class discussion. However, the freedom of students' must not transgress each other. Teachers must express their expectations from the student consistently in a direct and specific term and convey a positive attitude about the expectations and model the desired behaviour. Teachers must endeavour to leave an exemplary life as they are exemplars of behaviours and students do imitate them and the actions and comments of teachers make a tremendous impression on students. (Malone \& Tietjens, 2000; Matsumura, Slater \& Crosson, 2008).

Malone \& Tietjens (2000) in their study listed some rules which are necessary for teachers to note when making their classroom rules:

1. Rules must be rational and easily understood i.e. they should be clear and precise.

2. Rules must address the behaviour desired - the teacher should make rules that deal with the behaviour that is necessary for an optimum learning environment.

3. Too many rules may defeat behavioural or academic purposes.

4. Rules must fit within the structure of the institutions' code of conduct.

5. Rules must address ethics or moral behaviour desired - the teacher must create an understanding of the classroom rules and establish sound reasons for them. The student should be involved in the rulemaking process.

6. The rules must include roles of primary stakeholders' .i.e. parents, teachers, parents, and administrators.

Teachers' praise strategy, however, should be used to encourage the student in abiding by the rules. Teachers' praise is a comment that indicates the approval of students for following class rules. It reinforces and increases varieties of appropriate students' behaviour. The teacher could target it at the behaviour, attitude or skills that he wishes to increase in the students. (Partin et al. 2009; Pisacreta et al., 2011)

\section{Teaching Method factor}

This involves the ways the teacher tries to make the teaching delivery easy. It could be a traditional way of learning involving the delivery of lectures in classes or constructivism where students are expected to be active in the learning process by participating in the discussion or collaborative activities. In a flipped classroom model, constructivism is usually used. Irrespective of the method used, the participation of students is of great importance as allowing them to respond to questions or handle tasks that affect their appropriate academic and social behaviour. (Carpenter, 2006; Partin et al. 2009). 


\section{Mll Macrothink}

Journal of Studies in Education

ISSN 2162-6952

2019, Vol. 9, No. 4

Scholars (Adelodun, 1998, Oluokun \& Olayanju, 2000, Ogunsanya \& Adeyanju, 1999) have generally grouped teaching methods into two namely; learner-centred and teacher-centred. The method is learner-centred when the learner is the concern, focus, and centre of the teaching. The learner's interest in the teaching process is uppermost in the mind of the teacher as well as his teaching activities. The acquisition of knowledge and skills by the pupils takes priority in the mind of the teacher as he prepares for his teaching. Therefore, the learner is actively involved in the teaching-learning process. Examples of a learner-centred method of teaching are play-way, demonstration, discovery, group, assignment, project, excursion, field trip methods.

On the other hand, the teacher-centred method of teaching focuses attention on the teacher. The concern of the teacher is himself. How he will complete the syllabus and finish the course or subject he has to teach is his concern. He has little or no concern for his students. Whether the students are following him in the teaching process and whether the students eventually learn or not is less his concern. Examples of teacher-centred method include lectures, term paper presentations, long projects, etc.

The teaching method group-based learning or constructivism lab work, in-class exercise, oral presentation, applied projects, guest speakers. The method, however, should be selected based on most importantly the size of the class, the type, of course, it is whether it is practically oriented, theories oriented or discussion-oriented and availability of instructional facilities. The teachers must be creative enough to know which method to use and when to use them. (Casado 2000; Manurung 2012).

According to Manurung (2012), Creativity in the teaching learning process can be seen as teachers' effort to facilitate learning to achieve teaching goals. Creative teachers use everything they possess to actualize active learning to motivate learners. None of the teaching strategies is perfect in itself. It is expected for a creative teacher to choose a variety of effective learning strategies that underpin each other to engage learners and motivate them to learn. Therefore, the best teaching method is an Eclectic method. This involves the teacher applying the very good part of a teaching method to teach an appropriate step in his teaching process. The implication of this is that the teacher must be very familiar with all the methods of teaching and be able to see and use the most appropriate aspect of a method to teach the most appropriate step in his teaching process.

For example, a teacher can make use of lecture, demonstration, group, assignment methods within a teaching period. The teacher's introduction to a particular topic can be in the form of a lecture, i.e. the opening up of the concept. He then goes on to use a demonstration as he practically leads the students to see how such concept works or how it is in real-life situations. Further, he can group students and instruct them to demonstrate the concept among themselves and asks one or two groups to demonstrate to the whole class. The teacher finally gives them the assignment to do against the next contact as the class ends. 


\section{Replication for effective teaching-learning process}

It is necessary to consider some measures to be taken by the lecturers in the management of the students to ensure the effective teaching-learning process in the classroom.

The lecturer needs to be a role model for the students. The role modeling of the teacher includes punctuality at lectures, clean, neat and proper dressing, good conduct, speech, hard work and being disciplined. If the lecturer is up to the standard in those areas, it will go a long way in causing the students to look up to their teachers as an example. It will also stem from any anti-social behaviour among students.

Lecturers should endeavour to know their students very well. If possible identifying students by their names would be good. Calling them by their nicknames should be avoided, however. When a student is involved in an act of indiscipline in the classroom, calling such a student by his name will go a long way to help the student stop the act and much more if the student feels the lecturer does not know his/her name. It also includes the students been made to feel at home with the lecturer. They should feel safe with their lecturer and there should be no fear in the students towards the lecturer.

Also, the lecturer should build a relationship with their students. An integral part of effective teaching and learning process is to build a relationship with the students. Wolk (2003) as cited in (Dustova and Cotton, 2015) suggests that teachers must "win their students" heart while getting inside their students' heads. Research suggests that developing a relationship with students leads to fewer disruptive behaviours and an increase in academic performance. (Decker, Doma\& Christenson, 2007; Marzano and Marzano, 2003)

Building a relationship with students will involve showing empathy to students, creating interaction with individual students and being individualistic or recognizing individual differences among students. Meeting students on a one-on-one basis is very important in building relationships as it encourages effective teaching-learning processes in the tertiary institutions. The teacher's response to a student's need or challenge will make or mar the relationship between them and their students. When building relationships with students even small and negligible items matter. Hence, teachers should show maximum consideration for the feeling and circumstances of the learners.

Learners' rights and dignity should also be recognised by the teacher. According to the Teachers Code of Conduct (2005), teachers should have respect for the learner's right and dignity without prejudice to gender, race, religion, tribe, colour, physical characteristics, place of origin, age, etc. Freedom of speech, association, and interaction should be allowed among students.

Also, the Teachers Code of conduct (2005) says: Teachers should not use their position to humiliate, threaten, harass or blackmail any learner to submit to selfish motives or to engage in sexual misconduct, drug addiction, and trafficking, cultism, human trafficking, and other related offences. 


\section{Al Macrothink}

Journal of Studies in Education

ISSN 2162-6952

2019, Vol. 9, No. 4

Teachers should help students to develop positive confidence in themselves. They should appreciate that little effort of the students in their studies and motivate them for higher performance. They should encourage and not discourage students. Motivating words from teachers will go a long way to help weak students and high flyers on their toes.

The teachers should create a conducive atmosphere in the lecture hall. The atmosphere being referred to here is both physical and emotional. Students come to lecture with different emotional problems. Emotional issues can make or mar student learning at a time. The teacher/lecturer should understand and work on this to take his students to a positive emotional level at any teaching point. The first five minutes in the lecture can be used by the lecturer to bring his students to a positive level of emotional status favourable to learning. The teacher should ensure the lecture room being used is conducive by making sure there is proper lighting, the temperature is moderate; the room is safe and secured. It is not the duty of the teacher to provide all these but cases of an anomaly in the lecture room should be reported to the necessary departments for repairs or provision.

Teachers should prepare well for their lectures. It is not good enough for any teacher to go to lectures unprepared even though lesson plans/notes or notes of lessons are not written by teachers in tertiary institutions yet the lecturer should prepare well for lectures. The teacher should plan well for teaching apparatus/demonstration/illustrations that can help drive home the teaching to the mind of the students. They should make presentations and discussions lively and interesting and also be enthusiastic in their presentation. They should arouse students' interest from the beginning of the teaching and sustain it to the end. They should also prepare and ask adequate questions.

Lastly, the teacher/lecturer and the students should set some rules. Oliver \& Reschly (2007) affirms that "the use of rules is a powerful, preventive component of management of students for effective teaching and learning process. Rules establish the behavioural content of the teaching-learning environment what behaviour will be reinforced and the consequence of inappropriate behaviour". Most of the rules to set or reinforced should align with the institutions' rules, regulations, values, and norms.

\section{Dealing with Students' Misbehaviour in the Classroom}

Classroom interruption is a major challenge faced by lecturers (Simón \& Alonso-Tapia, 2016). In spite of all that might be done by the lecturer to manage and control students for effective teaching-learning process in tertiary institutions, there cannot but be some forms of misbehaviour among students because being students and humans, they are prone to some forms of misbehaviour in the lecture room.

The following misbehaviour in the classroom are common among students of tertiary institutions; lateness to lecture/laboratory/practical, noise-making, discussion among students, use of cell phones, receiving and making calls, improper dressing to lecture/laboratory, inattentiveness, sleeping, rudeness to lecturer, late assignments, tardiness, assault on another student and teacher and many more. 


\section{Mll Macrothink}

Few studies (e.g., Lewis et al., 2005; Biggs, 1998) have recommended that culture plays an important role in dealing with student misbehaviour in the classrooms in countries with diverse traditions and cultures. How a lecturer deals with students' misbehaviour during the teaching-learning process matters most. Taking into account that classroom management and classroom discipline are inextricably linked, the lecturer must develop an accurate sense of what is best for the class in every moment.

Student learning is the ultimate goal of teacher actions, classroom management must be considered as an instrument for student learning and not an end in and of itself. The rules can be set up by both the lecturer and the students which should be fully implemented. The rules should not just be there for being their sake. The rules should contain sanctions to those who break and praises and appreciation to those who keep them. However, the teacher should use his discretion in sanctioning the offenders as well as in appreciating the well-behaved ones.

Also, the teacher himself should live above board in terms of keeping the rules, he together with the students has set up. If there are any recalcitrant students he cannot tame after much love and efforts, he has to report such to a higher authority. Even though some teachers are active classroom managers, their students' commitment and academic achievement are low. Classroom misbehaviour is the most likely of these undesirable vectors of action in classes in which the teacher has difficulty keeping the lesson active (Lopes \& Santos, 2013).

Furthermore, the teacher should build obedience to school authority as a culture which if students imbibe will minimize lawlessness and enables students to appreciate sanctions that follow any act of disobedience to the school authority. An essential skill by teachers is classroom management while classroom misbehaviour is a major concern for most teachers but most specifically beginning teachers. In sum, successful teachers focus their actions on the engagement of students in class contents, not on the systematic amendment of students' misbehaviour, therefore maximizing teaching and learning time and preventing classroom misbehaviour from occurring (Lopes \& Oliveira, 2017).

\section{Policy Implications}

Managing and controlling classrooms for effective teaching-learning processes in the tertiary institution have some policy implications. It is important then to consider the following as needed policy matters to support the management and control of lecture rooms for an effective teaching-learning process.

Firstly, proprietors and proprietress (Stakeholder) of tertiary institutions should be able to provide a matter of policy state of art facilities in quantity to meet with the students, teaching and non-teaching staff of the institution. Through social dialogue, these can be achieved, the consensus at strategies for concrete action to improve the condition.

Management of the institution should develop good management and maintenance policies for all the teaching-learning as well as all other facilities in the institution. School management should create a good maintenance culture among all the stakeholders of the institution. (OECD, 2013). The policy should rest on the need to provide society with moral, 
intellectual and physical qualities and who have the required professional knowledge and skills (ILO/UNESCO, 2016).

Furthermore, the school management should make quick and constant repairs of damaged properties a policy. The policy should empower the physical planning, works, and services department in conjunction with the audit department to quickly do the repairs of the damaged properties with the approval of the chief executive of the institution drawing from the budgetary allocation for the purpose.

Besides, resource materials centre fully equipped should be put in place for lecturers, instructors and other teaching personnel consultants for necessary teaching aids material needed for their teaching functions.

Lastly, deans and heads of departments should be up and doing in their oversight functions of supervision of their younger colleagues in their teaching functions while they teach. There should be a policy that will make those senior colleagues responsible for the professional development of the young ones through adequate supervision. Or rather, the policy should make them mentors for the younger colleagues. Such roles they play must be documented so that it can be evident for the future.

\section{Conclusion}

What goes into the management of students in tertiary institutions for the effective teaching-learning process is more than the academic competence of the teacher. The knowledge of the subject matter only is not enough to assist in managing students for effective teaching-learning process. The teacher must be creative and innovative so that best practices in management theories and practice to ensure effective management of students for effective teaching-learning processes are adopted. It should be registered in the subconscious of the teacher that it is only when the students are properly managed that effective teaching can be achieved and students can acquire the expected knowledge and skills.

\section{References}

Adelodun, R. E. (1998) Introduction to Curriculum Studies. Ogbomoso: Ogunniyi Publishers

Ahmad, C. and Amirul, N. (2015). The effect of the physical learning environment on students' health, enjoyment and learning. Jurnal Pendidikan Sains\& Matematik Malaysia, $7(1), 47-55$.

Alabere, R. A. (2017). The Importance of Instructional Materials in Teaching of English as a Second Language. International Journal of Humanities and Social Science Invention , 6(9), $36-44$.

Amirul, N. J., Ahmad, C. N., Yahya, A. F., Abdullah, M. F. N. L., Noh, N. M., \& Adnan, M. (2013). The physical classroom learning environment. In 2nd International Higher Education Teaching and Learning Conference. 
Anderson, A., Hamilton, R. J., \& Hattie, J. (2004). Classroom climate and motivated behaviour in secondary schools. Learning environments research, 7(3), 211-225. https://doi.org/10.1007/s10984-004-3292-9

Barati, L. (2015). The Impact of Eye-contact between Teacher and Student on L2 Learning. Journal of Applied Linguistics and Language Research, 2(7), 222-227.

Casado, M. (2000). Teaching methods in higher education: A student perspective. Journal of Hospitality \& Tourism $\quad$ Education, 12(2), 65-70. https://doi.org/10.1080/10963758.2000.10685283

Carpenter, J. M. (2006). Effective teaching methods for large classes. Journal of Family \& Consumer Sciences Education, 24(2).13-23

Decker, D. M., Dona, D. P., \& Christenson, S. L. (2007). Behaviorally at-risk African American students: The importance of student-teacher relationships for student outcomes. Journal of School Psychology, 45(1), 83-109. https://doi.org/10.1016/j.jsp.2006.09.004

Dustova, G. and Cotton, S. (2015). Classroom Management Strategies. The CTE Journal, $2(3), 32-42$.

Effiong, O. E., \& Igiri, C. E. (2015). Impact of Instructional Materials in Teaching and Learning of Biology in Senior Secondary Schools in Yakurr LG A. International letters of $\begin{array}{llll}\text { Social and humanistic } & \text { 27-33. }\end{array}$ https://doi.org/10.18052/www.scipress.com/ILSHS.62.27

Enfield, J. (2013). Looking at the impact of the flipped classroom model of instruction on undergraduate multimedia students at CSUN. TechTrends, 57(6), 14-27. https://doi.org/10.1007/s11528-013-0698-1

Erwine, B., \&Heschong, L. (2002). Lighting for learning. In Lightfair International Seminar Preview.76-78

Gardiner, W.L. (1989). Forecasting, planning, and the future of the information society, In P. Goumain, (Ed.), High Technology Workplaces, Integrating technology, management, and design for productive work environments (pp. 27-39).

Gilavand, A., Gilavand, M., \&Gilavand, S. (2016). Investigating the impact of lighting educational spaces on learning and academic achievement of elementary students. International Journal of Pediatrics, 4(5), 1819-1828.

Hannah, R. (2013). The effect of classroom environment on student learning.Honors Theses. Paper 2375

Hui, S. C., \& Cheng, M. K. K. (2008). Analysis of Effective Lighting Systems for University Classrooms.In Proceedings of the Henan-Hong Kong Joint Symposium.

Khan, N., Mohammad, N., Shah, N., \&Farid, N. (2016). A Study of the Use of Eye Contact in Teaching Learning Process at Secondary Level in District Peshawar. Language in India, 16(4). 81-98 


\section{$\triangle$ Macrothink}

Lopes, J., \& Santos, M. (2013). Teachers' beliefs, teachers' goals and teachers' classroom management: A study with primary teachers. Revista de Psicodidáctica. Journal of Psychodidactics, 18(1), 5-24. https://doi.org/10.1387/RevPsicodidact.4615

Lopes, J., \& Oliveira, C. (2017). Classroom discipline: Theory and practice. In J. P. Bakken (Ed.), Classrooms: Academic content and behavior strategy instruction for students with and without disabilities (Vol. 2, pp. 231-253). New York: Nova Science Publishers.

Malone, B. G., \& Tietjens, C. L. (2000). Re-examination of classroom rules: The need for clarity and specified behavior. Special Services in the Schools, 16(1-2), 159-170. https://doi.org/10.1300/J008v16n01_11

Manurung, K. (2012). Creative teachers and effective teaching strategies that motivates learners to learn. Indonesian Journal of Science Education, 2(1), 1-8.

Marais, P. (2016). "We can't believe what we see": Overcrowded classrooms through the eyes of student teachers. South African Journal of Education,36(2).1-10 https://doi.org/10.15700/saje.v36n2a1201

Marzano, R. J., \& Marzano, J. S. (2003). The key to classroom management. Educational Leadership 6(1). 6-23

Matsumura, L. C., Slater, S. C., \&Crosson, A. (2008). Classroom climate, rigorous instruction and curriculum, and students' interactions in urban middle schools. The elementary school journal, 108(4), 293-312. https://doi.org/10.1086/528973

OECD. (2013). Synergies for Better Learning: An International Perspective on Evaluation and Assessment, OECD Reviews of Evaluation and Assessment in Education, OECD Publishing.

Ogunsanya, M. \& Adeyanju, A. ( Ed.1999) Fundamental Principles of of Education. Oyo; Andrian Publication Series.

Oliver, R. M., and Reschly, D. J. (2007). Effective Classroom Management: Teacher Preparation and Professional Development. TQ Connection Issue Paper. National comprehensive center for teacher quality, pp. 1-19

Oluokun, O. \& Olayanju, O. (2000). An Introduction to Principles and Methods of Teaching Lagos: Sibis Ventures

Opoku-Asare, N. A., Agbenatoe, W. G., \& DeGraft-Johnson, K. G. (2014). Instructional strategies, institutional support and student achievement in general knowledge in art: Implications for visual arts education in Ghana.

Pane, D. M. (2010). Viewing classroom discipline as negotiable social interaction: A communities of practice perspective. Teaching and teacher education, 26(1), 87-97. https://doi.org/10.1016/j.tate.2009.05.002 


\section{$\Lambda$ Macrothink}

Partin, T. C. M., Robertson, R. E., Maggin, D. M., Oliver, R. M., \&Wehby, J. H. (2009). Using teacher praise and opportunities to respond to promote appropriate student behavior. Preventing School Failure: Alternative Education for Children and Youth, 54(3), 172-178. https://doi.org/10.1080/10459880903493179

Pisacreta, J., Tincani, M., Connell, J. E., \& Axelrod, S. (2011). Increasing teachers' use of a 1: 1 praise-to-behavior correction ratio to decrease student disruption in general education classrooms. Behavioral Interventions, 26(4), 243-260. https://doi.org/10.1002/bin.341

Samani, S. A., \& Samani, S. A. (2012). The impact of indoor lighting on students' learning performance in learning environments: A knowledge internalization perspective. International Journal of Business and Social Science, 3(24), 127-136

Shah, J. and Inamullah, M. (2012). The Impact of Overcrowded Classroom on the Academic performance of the Students at Secondary Level. International Journal of Research in Commerce, Economics and Management, 2(6), (June) ISSN 2231-4245, India

Simón, C., \& Alonso-Tapia, J. (2016). Positive classroom management: Effects of disruption management climate on behaviour and satisfaction with teacher. Revista de Psicodidactica, 21(1), 65-86. https://doi.org/10.1387/RevPsicodidact.13202

Strayer, J. (2007). The effects of the classroom flip on the learning environment: A comparison of learning activity in a traditional classroom and a flip classroom that used an intelligent tutoring system (Doctoral dissertation, The Ohio State University).

Teachers Registration Council of Nigeria. (2005). Teachers Code of Conduct Abuja, Nigeria: Teachers Registration of Council of Nigeria.

The ILO/UNESCO Recommendation concerning the Status of Teachers (1966) and the UNESCO Recommendation concerning the Status of Higher-Education Teaching Personnel (1997) with a revised Foreword and Users' Guide, 2016. International Labour Office, Sectoral Policies Department, Geneva,

Vijayan, P., Chakravarthi, S., \& Philips, J. A. (2016). The role of teachers' behaviour and strategies in managing a classroom environment. International Journal of Social Science and Humanity, 6(3), 208. https://doi.org/10.7763/IJSSH.2016.V6.644

Wannarka, R., \& Ruhl, K. (2008). Seating arrangements that promote positive academic and behavioural outcomes: A review of empirical research. Support for learning, 23(2), 89-93. https://doi.org/10.1111/j.1467-9604.2008.00375.x 